\title{
Docência e inclusão: os desafios e os sentimentos de professores de educação física na educação básica
}

\author{
Hugo Norberto Krug ${ }^{1}$ \\ Rodrigo de Rosso Krug ${ }^{2}$ \\ Moane Marchesan $\mathrm{Krug}^{3}$
}

\section{Resumo}

O estudo objetivou analisar as percepções de professores de Educação Física (EF) da Educação Básica (EB), da rede pública de ensino, de uma cidade da região central do Estado do Rio Grande do Sul (Brasil), sobre os desafios e os sentimentos expressos na docência com alunos com deficiência incluídos nas aulas de EF Escolar. Caracterizamos a pesquisa como qualitativa do tipo estudo de caso. O instrumento de pesquisa foi uma entrevista com vinte professores, tendo as informações interpretadas pela análise de conteúdo. Concluímos que, apesar do respaldo legal, o sistema educacional até hoje, não se estruturou para o oferecimento da Educação Inclusiva, pois foram apontados vários desafios que originaram sentimentos negativos que são fonte de sofrimento para os docentes estudados e, por consequência, dificultam a qualidade do ensino proporcionado aos alunos com deficiência.

Palavras-chave: Educação Física. Educação Física Escolar. Inclusão. Desafios. Sentimentos.

\begin{abstract}
The study was aimed to analyze the perceptions of Physical Education (PE) teachers of the Basic Education (BE), of the public school network, of a city in the central region of the State of Rio Grande do Sul (Brazil), about the challenges and feelings expressed in teaching with students with disabilities included in the school PE clasrrom. We characterize the research as qualitative of the case study type. The research instrument was an interview with twenty teachers, having the information interpreted by the content analysis. We conclude that, still of the legal support, the educational system until today, has not been structured to the offer of Inclusive Education, because it was pointed several challenges that originated negative feelings that are source of suffering for the teachers studied and, consequently, hamper the quality of the education provided to students with disabilities.
\end{abstract}

Keywords: Physical Education. School Physical Education. Inclusion. Challenges. Feelings.

\footnotetext{
${ }^{1}$ Licenciado em Educação Física (UFPel); Mestre em Ciência do Movimento Humano (UFSM); Doutor em Educação (UNICAMP/UFSM); Doutor em Ciência do Movimento Humano (UFSM).

${ }^{2}$ Licenciado em Educação Física pela Universidade de Cruz Alta(UNICRUZ); Mestre em Ciências do Movimento Humano (UDESC); Doutor em Ciências Médicas (UFSC); Professor dos Cursos de Licenciatura e Bacharelado da Universidade de Cruz Alta (UNICRUZ); Professor do Programa de Pós-Graduação em Atenção Integral à Saúde (Mestrado) da UNICRUZ.

${ }^{3}$ Licenciada em Educação Física (UNICRUZ); Fisioterapeuta (UNICRUZ); Mestre em Educação Física (UFPel); Doutora em Educação Física (UFSC); Professora do Curso de Bacharelado em Educação Física da Universidade Regional do Noroeste do Estado do Rio Grande do Sul (UNIJUÍ).
} 
As considerações introdutórias

Segundo Krug et al. (2018b, p.59), "[e]m tempos recentes, podemos constatar uma intensificação de investigações sobre a inclusão escolar de pessoas com deficiência”. Nesse contexto, destacamos que, neste estudo, o termo pessoa (aluno) com deficiência foi utilizado para se referir à pessoa que tem "[...] impedimentos de longo prazo, de natureza física, mental ou sensorial que, em interação com diversas barreiras, podem ter restringida sua participação plena e efetiva na escola e na sociedade" (BRASIL, 2008, p.9). No entanto, é necessário ressaltar que, para Sassaki (2005), os movimentos mundiais de pessoas com deficiência, incluindo os do Brasil, debateram o nome pelo qual elas (pessoas com deficiência) desejavam ser chamadas. Então, mundialmente, esta questão já está fechada. Querem ser chamadas de 'pessoas com deficiência'. Esse termo faz parte do texto da Convenção Internacional para Proteção e Promoção dos Direitos e da Dignidade das Pessoas com Deficiência, aprovada pela Organização das Nações Unidas (ONU).

Diante desse cenário, mencionamos Monteiro e Earp (2011) que colocam que, a inclusão escolar de pessoas com deficiência é fruto de um movimento maior, o de inclusão social. Segundo Sassaki (2005), inclusão social consiste em adequar os sistemas sociais gerais da sociedade para que sejam eliminados os fatores que excluem certas pessoas do seu meio e mantêm afastadas aquelas que foram excluídas. Nesse direcionamento de propósito, Monteiro e Earp (2011) salientam que as práticas de inclusão estão se tornando uma realidade no Brasil.

Nesse sentido, Krug et al. (2018a, p.2) lembram que "o debate sobre a inclusão escolar e as questões que se referem à participação de pessoas com deficiência no ensino regular, no Brasil, é decorrente da Constituição Brasileira (BRASIL, 1988) e efetivada pela Lei de Diretrizes e Bases da Educação Nacional - LDBEN - n.9394 (BRASIL, 1996)".

Assim, de acordo com Krug et al. (2018b, p.59), "[n]o contexto escolar, sabendo do papel que a escola possui no processo de inclusão", esses autores destacam "a disciplina de Educação Física como um importante componente obrigatório do currículo escolar, da [E]educação [B]ásica”, que, conforme Telles e Krug (2014, p.3), deve garantir "um ensino de qualidade para todos os alunos (com deficiência ou não)".

Dessa forma, voltamos nossos olhares investigativos para a disciplina de Educação Física (EF) e seu professor, bem como para a temática da inclusão escolar. Nessa direção de intenção, constatamos a existência de vários estudos (CARVALHO; ARAÚJO, 2018; KRUG et al., 2018a; KRUG et al., 2018b; KRUG et al., 2017a; KRUG et al., 2017b; KRUG et al., 2016; TELLES; KRUG, 2014; CONCEIÇÃO; KRUG; VENSON, 2013) que apontam para as dificuldades, inseguranças e incertezas a respeito da implementação do processo de inclusão escolar.

Entretanto, nesse contexto, nos deparamos com outra preocupação que são as percepções de professores de EF da Educação Básica (EB) sobre os seus sentimentos frente aos desafios nas aulas de Educação Física Escolar (EFE) com alunos com deficiência (grifo nosso a partir desse momento). Assim, nos referimos à Krug (2017, p.3) que diz que, “[...] o ofício da docência, [...], é fonte de emoções, sentimentos [...] e que estes sentimentos assumem uma importância impar, pois, o estudo dos mesmos permite o conhecimento dos aspectos peculiares à escola e aos docentes $[\ldots]$ que podem interferir direta ou indiretamente no ensino $[\ldots] "$. 
Nesse sentido, devido aos grandes desafios que o sistema educacional, bem como as disciplinas que o integram, e, no caso específico deste estudo o foco é a EF, que "[...] vem sofrendo com a inclusão", torna-se fundamental "a escuta e a problematização das percepções dos próprios professores de EF" sobre essa temática, pois "esses podem apontar dimensões importantes a serem consideradas no trabalho docente" (KRUG et al., 2018b, p.60). Já, Costa (2017, p.4) afirma que

[...] um passo importante para viabilizar uma [E]ducação [I]nclusiva de qualidade é criar condições para o professor, agente das ações mais diretas no processo de inclusão de alunos com defíciência em classes regulares, revelar seus sentimentos_frente às dificuldades (dilemas/desafios) vividas em sala de aula. (inserção nossa).

Consequentemente, embasando-nos nas premissas anteriormente descritas, formulamos a seguinte questão problemática do estudo: quais são as percepções de professores de EF da EB, da rede pública de ensino, de uma cidade da região central do Estado do Rio Grande do Sul-RS (Brasil), sobre os desafios e os sentimentos expressos na docência com alunos com deficiência incluídos nas aulas de EFE? A partir dessa indagação, o estudo teve como objetivo geral analisar as percepções de professores de EF da EB, da rede pública de ensino, de uma cidade da região central do Estado do RS (Brasil), sobre os desafios e os sentimentos expressos na docência com alunos com deficiência incluídos nas aulas de EFE.

Justificamos a realização deste estudo pela necessidade de se estudar o tema inclusão escolar, e, nesse sentido, embasamo-nos em Rena et al. (2010, p.3) quando afirmam que

[...] desenvolver um estudo em que se possa identificar e entender as dificuldades dos professores na docência com os alunos deficientes é essencial para iniciar um processo de descoberta para aprimorar práticas pedagógicas, mas principalmente para dar maior espaço ao lugar de direito desses alunos, muitas vezes excluídos por medo e falta de preparo das instituições educadoras.

Além disso, consideramos que pesquisas desta natureza oferecem subsídios para reflexões que podem despertar modificações no contexto da formação inicial e continuada de professores de EF, as quais podem contribuir para a melhoria desses profissionais na atuação docente na escola, principalmente com a inclusão escolar.

\section{Os procedimentos metodológicos}

Caracterizamos esta pesquisa como qualitativa do tipo estudo de caso. Segundo Goldenberg (1997), na pesquisa qualitativa o pesquisador não se baseia na representatividade numérica do grupo, mas na compreensão aprofundada de um grupo social, de uma organização, de uma instituição, de uma trajetória. Já, conforme Ponte (2006), o estudo de caso é uma investigação sobre uma situação específica, procurando descobrir o que há nela de mais essencial e característico e, desse modo, contribuir para a compreensão global de certo fenômeno de interesse.

Assim, neste estudo, o caso investigado referiu-se aos professores de EF da EB, da rede pública de ensino, de uma cidade da região central do Estado do RS (Brasil). 
Dessa forma, a justificativa da escolha da forma de pesquisa qualitativa e estudo de caso foi devido "[...] à possibilidade de se analisar um ambiente em particular, onde se levou em conta o contexto social e sua complexidade para compreender e retratar uma realidade em particular e um fenômeno em especial [...]" (KRUG et al., 2017c, p.59-60), 'as percepções de professores de EF da EB, sobre os desafios e os sentimentos expressos na docência com alunos com deficiência incluidos nas aulas de EFE'.

A coleta de informações foi realizada por meio de entrevista semiestruturada que, segundo Triviños (1987, p.45), "[...] valoriza a presença do investigador, oferece todas as perspectivas possíveis para que o informante alcance a liberdade e a espontaneidade necessárias, enriquecendo a investigação".

A interpretação das informações coletadas foi efetuada mediante procedimentos básicos da análise de conteúdo, como a leitura flutuante, o agrupamento de respostas e a categorização (TURATO, 2003).

Participaram do estudo vinte professores de EF da EB, da rede pública municipal de ensino, de uma cidade da região central do Estado do RS (Brasil), que possuíam alunos com deficiência em suas aulas. Essa decisão está em consonância com o dito por Santos e Moretti-Pires (2012, p.165) de que "[a] amostragem intencional é uma das estratégias de amostragem mais utilizadas nas pesquisas qualitativas. De acordo com essa estratégia, os participantes são pré-selecionados conforme os critérios relevantes para o objeto de investigação".

Quanto aos aspectos éticos vinculados às pesquisas científicas, destacamos que todos os participantes assinaram o Termo de Consentimento Livre e Esclarecido e suas identidades foram preservadas.

Convém salientarmos que, quanto às 'características pessoais', a 'maioria' (quatorze) dos professores de $\mathrm{EF}$ da EB estudados era do 'sexo feminino' e a 'minoria' (seis) do 'sexo masculino'. Para justificar essa disparidade de representantes de cada sexo, citamos Conceição et al. (2004) que colocam que existe uma superioridade do número de docentes de EF do sexo feminino, no magistério público municipal, da referida cidade, palco deste estudo. Também constatamos que as 'idades' dos professores de EF da EB estudados estavam na 'faixa etária de 24 à 49 anos'. Sobre esse agrupamento etário, mencionamos Luizari (2006) quando afirma que a vida é composta por ciclos e esses estão relacionados, geralmente, às mudanças pelas quais as pessoas passam, mas ressalta que nenhum é mais importante que o outro, pois cada ciclo de vida é influenciado pelo que ocorreu antes e irá afetar o que virá depois.

Já, sobre as 'características profissionais', como já destacamos anteriormente, 'todos' (vinte) eram 'formados em Licenciatura em EF', possuíam 'de quatro à vinte e cinco anos de tempo de serviço' e eram 'lotados em uma rede de ensino municipal' de uma cidade da região central do Estado do RS.

\section{Os resultados e as discussões}

Os resultados e as discussões foram orientados e explicados a partir do objetivo geral do estudo, pois esse representou a única categoria de análise existente, fato esse em consonância com o colocado por Minayo; Deslandes e Gomes (2007) de que a(s) categoria(s) de análise pode(m) ser gerada(s) previamente à pesquisa de campo.

Considerando então que os desafios e os sentimentos dos professores de EF da EB na sua docência com alunos com deficiência inclusos nas aulas de EFE foi a categoria de análise, inicialmente, achamos necessário citarmos Marques et al. (2015, p.189) que consideram desafio como "a possibilidade de enfrentamento dos 
problemas e/ou dificuldades definidos(as) como um obstáculo, uma situação difícil ou ainda algo de difícil solução". Consequentemente, também, acreditamos ser importante mencionarmos Luft (2000) que afirma que a palavra sentimento significa ato ou efeito de sentir(-se). É a aptidão para sentir, disposição para se comover, se impressionar, perceber e apreciar algo; sensibilidade.

Nesse contexto, lembramos Gonçalves (1992) quando diz que a função do professor subentende ensinar, isto é, transmitir conhecimentos específicos e diversificados aos alunos, organizar o trabalho em aula, manter a disciplina, estabelecer relações com as pessoas, ter um papel de educador junto aos alunos e, ainda, promover a animação de atividades, etc., o que implica o surgimento de desafios, isto é, a possibilidade de enfrentamento de problemas e/ou dificuldades na prática docente que são geradores, antes, durante e depois e, também, o surgimento de emoções, sentimentos no docente, que podem atrapalhar a prática pedagógica.

Dessa forma, emergiram, nas percepções dos professores de EF da EB estudados, 'seis unidades de significados'. De acordo com Molina Neto (2004), unidades de significados são como enunciados dos discursos do informante que são significativos, tanto para o colaborador (pesquisado), quanto para o pesquisador, sendo atribuídos aos pressupostos teóricos da pesquisa. Dessa maneira, as unidades de significados foram descritas a seguir.

'A existência de alunos inclusos nas aulas de $\mathbf{E F}$ ' foi um dos desafios (a primeira unidade de significado) que causou os sentimentos de 'ansiedade', 'medo', 'pânico', 'impotência' e 'insegurança' aos professores de EF da EB estudados (grifo nosso a partir desse momento). Esse fato está em consonância com os achados de Anjos (2008), Sagrilo e Paim (2009), Rena et al. (2010) e Costa (2017). Anjos (2008) diz que, em relação aos sentimentos dos professores, ao se depararem com alunos com deficiência, há, tanto o sentimento de pânico diante da situação nova, quanto o sentimento de medo de cometer erros graves, bem como o sentimento de impotência por não saber como proceder. De acordo com Rena et al. (2010, p.8), "[o] sentimento de ansiedade dos professores diante do cenário da inclusão é muito evidenciado". Também Costa (2017) constatou que os sentimentos de professores da EB frente à missão de atuar com a inclusão do aluno com deficiência em sala de aula com alunos sem deficiência, apontados como mais importantes, foram ansioso e inseguro. Já, Sagrilo e Paim (2009) destacam que ocorre a presença dos sentimentos de medo e de insegurança nos professores de EF ao receberem alunos com deficiência em suas aulas. Ressaltam que a origem desses sentimentos é a sensação que o professor tem de não conseguir cumprir o seu papel e de não saber como interagir com esses alunos, sendo então isso, um dos maiores desafios no processo de inclusão. Diante desse contexto, citamos Manzini (2002) quando alerta que apenas razões legais assegurando a matrícula do aluno com deficiência na escola regular não garante a prática da inclusão nas aulas das diversas disciplinas do currículo escolar, incluída a EF. Assim, nesse contexto, podemos inferir que a existência de alunos inclusos nas aulas de EFE é um desafio na docência em EF na EB e gera os sentimentos de angústia, medo, pânico, impotência e insegurança nos professores.

'A falta de preparo/capacitação do próprio professor em lidar com alunos com deficiência nas aulas de $\boldsymbol{E F}$ ' foi outro dos desafios (a segunda unidade de significado) que causou os sentimentos de 'medo', 'insegurança' e 'angústia' aos professores de EF da EB estudados. A respeito desse fato, mencionamos Tessaro (2007) ao colocar que a própria falta de preparo e capacitação para trabalhar com alunos com deficiência é um dos fatores que explicam os sentimentos de medo e insegurança dos professores na docência. Entretanto, segundo Serra (2006), o professor deverá ser preparado com uma formação contínua para melhor atender e compreender seus alunos 
com deficiência, mas a realidade não acontece dessa maneira, o que contribui para a insegurança e a angústia do professor. Já, Rena et al. (2010, p.10) destacam que os "profissionais relatam que sabem que o aluno de inclusão demanda atenção especial, mas reconhecem ser impossível se dedicar a esse aluno por estarem sozinhos frente a um grande número de alunos". Assim, a insegurança surge na prática pedagógica por que “[a] relação pedagógica não é satisfatória, pois como não se sentem devidamente preparad[o]s [...], acabam não conseguindo ter certeza sobre sua prática e seus resultados" (RENA et al., 2010, p.9). Ainda Rena et al. (2010, p.11) colocam que "[o] sentimento de angústia está mais relacionado à expectativa da nova situação que se aproxima ou à nova postura didática necessária para lidar com o aluno da inclusão". Também Naujorks et al. (2000) acreditam que a proposta da escola inclusiva mesmo estando diretamente ligada aos anseios dos docentes, causa angústias e medos aos mesmos, pois muitos ainda não se sentem preparados para exercer a cidadania junto à diversidade humana. Diante desse contexto, Telles e Krug $(2014$, p.5) salientam que "[...] o despreparo dos professores das disciplinas para trabalhar com alunos com deficiência" é uma das "desvantagens da inclusão dos alunos com deficiência na escola regular”. Krug et al. (2016, p.60) acrescentam que “[a] falta de capacitação do professor de EF em lidar com os alunos com deficiência [...]" é um dos desafios/dilemas/dificuldades encontrados na EF Inclusiva. Frente a esse cenário, podemos inferir que a falta de preparo/capacitação do próprio professor em lidar com alunos com deficiência nas aulas de EFE é um desafio na docência em EF na EB e gera os sentimentos de medo, insegurança e angústia nos professores.

'A falta de acessibilidade/infraestrutura da escola' foi mais outro dos desafios (a terceira unidade de significado) que causou os sentimentos de 'medo' e 'insegurança' aos professores de EF da EB estudados. Quanto a esse fato, nos reportamos a Tessaro (2007) ao lembrar que são inúmeros os fatores que explicam os sentimentos de medo e insegurança nos professores ao trabalharem com alunos com deficiência, sendo um deles, a falta de infraestrutura das escolas. Esse fato está em consonância com o estudo de Krug et al. (2016, p.60) que constataram que "[a] falta de infraestrutura e materiais na escola" é um dos dilemas/desafios/dificuldades da EFE inclusiva. Nesse sentido, Krug et al. (2018b) acrescentam que 'a falta de acessibilidade/infraestrutura na escola' é uma das desvantagens da inclusão de alunos com deficiência nas aulas de EF. Reforçando esses fatos destacados anteriormente, mencionamos Lehnard; Manta e Palma (2011) que colocam a existência de barreiras arquitetônicas no ambiente escolar que dificultam ou impedem o acesso e a inclusão de alunos com deficiência. Nesse sentido, Fernandes; Vargas e Falkenback (2009) salientam que a acessibilidade e a inclusão são inseparáveis. A acessibilidade é fundamental para o profissional que trabalha em educação, bem como ao aluno que está incluído, pois assim proporciona ao estudante um aprendizado melhor através de estratégias de ensino e de conteúdo adequados, como também proporciona acesso aos locais e estruturas onde serão transmitidos esses conhecimentos, assim caminhando para o processo inclusivo. Ainda Souza e Miranda (2010) ressaltam que, frente à proposta de inclusão, as escolas necessitam estar cada vez mais preparadas para poderem assimilar mecanismos que objetivam atender os alunos com deficiência, fazendo com que os mesmos participem das aulas, independentemente de suas limitações físicas. Diante desse quadro, podemos inferir que a falta de acessibilidade/ infraestrutura da escola é um desafio na docência em EF na EB e gera os sentimentos de medo e insegurança nos professores. 
'O não atendimento dos alunos com deficiência por professores especializados' foi também outro dos desafios (a quarta unidade de significado) que causou o sentimento de 'insatisfação' aos professores de EF da EB estudados. Rena et al. (2010, p.10) destacam que os professores declaram "[...] a necessidade de ter ao seu lado um profissional especializado, de preferência acompanhando o aluno de inclusão". Também Diniz e Rahme (2004) ressaltam justamente sobre essa necessidade, de ter em aula, junto com o professor, um acompanhante profissional especializado que proporcionaria a integração do mesmo com o ambiente. Nesse sentido, Krug et al. (2016, p.60) destacam que "[...] a falta de apoio técnico ao professor de EF" é um dos dilemas/desafios/ dificuldades da EFE Inclusiva. Assim, diante dessa realidade, de falta de auxílio, Rena et al. (2010) colocam que os professores manifestam um sentimento de insatisfação, pois acreditam que, sem esse auxílio, o processo de inclusão é prejudicado, bem como o aprendizado do aluno com deficiência. Nesse direcionamento de situação, Serra (2006) chama à atenção de que a inclusão, de fato, não ocorre somente com a socialização, mas sim, quando há o aprendizado. Esclarecendo melhor, citamos Freitas e Leucas (2009) quando dizem que o termo incluir é garantir que todos os alunos venham a ter acesso ao conhecimento historicamente acumulado, sistematizado, organizado e ampliado, e também que dêem significado e sentido as suas aprendizagens, valorizando as possibilidades das diferenças serem manifestadas e respeitadas, sem discriminação. Assim, para Telles e Krug (2014, p.5), “[...] o não atendimento dos alunos com deficiência por professores especializados" é uma das "desvantagens da inclusão de alunos com deficiência na escola regular". Também Krug et al. (2018b) destacam esse mesmo fato. Assim, frente a esse contexto, podemos inferir que o não atendimento dos alunos com deficiência por professores especializados é um desafio na docência em EF na EB e gera o sentimento de insatisfação nos professores.

'A discriminização social dos alunos com deficiência' foi mais um dos desafios (a quinta unidade de significado) que causou os sentimentos de 'medo' e 'insegurança' aos professores de EF da EB estudados. Sobre esse fato, apontamos Tessaro (2007) ao destacar que a discriminização social dos alunos com deficiência é um dos fatores que explicam o surgimento de sentimentos como o medo e a insegurança nos professores em sua docência. Já, Lima; Santos e Silva (2007/2008) colocam que, na escola, existe, em diversos casos, a resistência e a não aceitação dos alunos com deficiência pelos colegas nas aulas. Esse fato está em consonância com o estudo de Krug et al. (2016, p.61) que constataram que "[o] preconceito dos alunos com os colegas com deficiência" é um dos dilemas/desafios/dificuldades da EFE Inclusiva. Já, Krug et al. (2018b, p.65) destacam que, “[o] preconceito dos alunos com os colegas com deficiência" é uma das desvantagens da inclusão de alunos com deficiência nas aulas de EF. Reforçando esse fato, citamos Krug $(2002$, p.16) que coloca que "[a] diversidade humana é muito ampla. Mesmo assim, existem pessoas que ainda não compreenderam, muito bem, as diferenças e as deficiências que todos possuem, gerando estigmas, preconceitos e impondo rotulações [...]" como é o caso das pessoas com deficiência. Nesse sentido, segundo Conceição; Souza e Krug (2010, p.4), “[é] de fundamental importância trabalhar com os alunos sobre a inclusão e, com isso evitar qualquer tipo de discriminação dentro de nossa sociedade, contribuindo na formação de pessoas que serão capazes de entender a diversidade". Dessa forma, considerando esse cenário, podemos inferir que a discriminação social dos alunos com deficiência é um desafio na docência em EF na EB e gera os sentimentos de medo e insegurança nos professores. 
'A não participação do aluno com deficiência nas aulas' foi também outro dos desafios (a sexta e última unidade de significado) que causou o sentimento de 'impotência' aos professores de EF da EB estudados. Esse fato está em consonância com o colocado por Lourencetti e Mizukami (2002) de que integram a prática pedagógica dos professores as dificuldades, os problemas, os dilemas, os desafios e que, em algumas situações vivenciadas, os docentes parecem sentir-se impotentes, isto é, limitados para agir. A respeito da não participação do aluno com deficiência nas aulas, isso pode estar ligado a três possibilidades: a falta de acessibilidade no local da aula, ao próprio aluno ou ao professor. Quanto aos sentimentos, além da impotência, é o medo, o que não foi mencionado pelos professores de EF da EB estudados. Nesse sentido, Seabra Junior (2006, p.80) afirma que a metodologia do professor e as ações adotadas pelo professor são decisivas na participação do aluno com deficiência nas aulas e, com isso, destaca "a influência da ação docente na participação ou distanciamento dos alunos, nas aulas de Educação Física". Palma e Lehnhard (2012) salientam que a não participação do aluno com deficiência nas aulas de EF pode ser gerada por uma atitude de superproteção do professor pelo temor que o mesmo se machuque. Já, Lima e Silva $(2009$, p.27) colocam que a atividade de impedir que o aluno explore os espaços e movimentos por medo que se machuque, assinala uma superproteção que é classificada como barreira atitudinal. As barreiras atitudinais são, segundo os autores, "a utilização de rótulos, adjetivações, substantivação da pessoa com deficiência como um todo deficiente". Conforme Palma e Lehnhard (2012), quando observamos uma pessoa com deficiência, o que chama a atenção é a deficiência, fazendo com que esqueçamos que esses indivíduos também são capazes. Partindo do senso comum, são criados os pré-conceitos de que são seres incapacitados de realizar atividades corriqueiras como uma pessoa sem deficiência. Dessa maneira, considerando esse cenário, podemos inferir que a não participação do aluno com deficiência nas aulas é um desafio na docência em EF na EB e gera o sentimento de impotência nos professores.

Assim, esses foram os desafios e os sentimentos, frente à inclusão de alunos com deficiência nas aulas de EFE, nas percepções dos professores de EF da EB estudados. Nesse sentido, consideramos importante citarmos Costa $(2017$, p.6) ao afirmar que

[o]s professores, ao revelarem seus sentimentos aliados às dificuldades (dilemas/desafios) da prática da [E]ducação [I]nclusiva, nos fornecerão indícios importantes para a compreensão da forma como se aproximam da realidade, como lidam com suas contradições, enfim, como configuram sua dimensão subjetiva (inserção nossa).

Ainda Costa (2017, p.6) destaca que o que dificulta o processo de inclusão escolar, entre outros fatores, é a falta de "[...] espaço para ouvir o que estes profissionais (os professores) têm a dizer a respeito dos seus sentimentos, atitudes diante da pessoa com deficiência e da inclusão escolar [...]" (inserção nossa).

Ao efetuarmos uma 'análise geral', sobre os desafios frente à inclusão de alunos com deficiência nas aulas de EFE, nas percepções dos professores de EF da EB estudados, constatamos que uma 'metade' (três do total de seis) dos desafios estão diretamente 'ligados à estrutura da escola/sistema educacional' (primeira, terceira e quarta unidades de significados) e, uma outra 'metade' (três do total de seis) está dividida entre os desafios diretamente 'ligados aos alunos da EB' (duas do total de três: quinta e sexta unidades de significados) e os diretamente 'ligados aos próprios professores, ou seja, a si mesmos' (uma do total de três: segunda unidade de significado). Esse fato está em consonância com o estudo de Krug et al. (2016) que constataram que a metade dos 
dilemas/desafios/dificuldades da EF Inclusiva são de cunho estrutural. Assim, a partir dessa constatação, podemos inferir que os desafios da inclusão de alunos com deficiência nas aulas de EFE giram, principalmente, em torno da dimensão estrutural da escola e/ou sistema educacional.

Ao realizarmos uma 'análise geral' sobre os sentimentos expressos frente à inclusão de alunos com deficiência nas aulas de EFE, nas percepções dos professores de EF da EB estudados, constatamos 'a existência de um rol de sete sentimentos expressos'. Foram eles: a 'insegurança' (presente em quatro unidades de significados: primeira, segunda, terceira e quinta), o 'medo' (presente também em quatro unidades de significados: primeira, segunda, terceira e quinta), a 'impotência' (presente em duas unidades de significados: primeira e sexta), a 'ansiedade' (presente em uma unidade de significado: primeira), a 'angústia' (presente também em uma unidade de significado: segunda), o 'pânico' (presente também em uma unidade de significado: primeira) e a 'insatisfação' (presente igualmente em uma unidade de significado: quarta). Esse fato está em consonância com o manifestado por Amaral (1994) quando afirma que existe uma hegemonia emocional sobre o racional diante de situações desconhecidas, como, por exemplo, o contato com a pessoa com deficiência no processo de inclusão. Destaca que tal contato está permeado de sentimentos, tais como, o medo, entre outros. Ressalta ainda que, mesmo que não se admita ou que os sentimentos sejam inconscientes, eles estão presentes com mais frequência que imaginamos. Já, Costa (2017) diz que os sentimentos mais assíduos revelados pelos professores, frente à Educação Inclusiva, apresentam-se, os sentimentos, tais como, insegurança, ansiedade e angústia, entre outros. Assim, a partir dessa constatação, podemos inferir que os sentimentos expressos frente aos desafios da inclusão de alunos com deficiência nas aulas de EFE perpassam pela insegurança, medo, impotência, ansiedade, angústia, pânico e insatisfação.

Ainda, constatamos que o desafio que desperta o maior número de sentimentos foi 'a existência de alunos inclusos nas aulas de EF' (primeira unidade de significado) com cinco (ansiedade, medo, pânico, impotência e insegurança), seguindo-se 'a falta de preparo/capacitação do próprio professor em lidar com alunos com deficiência nas aulas de EF' (segunda unidade de significado) com três (medo, insegurança e angústia), 'a falta de acessibilidade/infraestrutura da escola' (terceira unidade de significado) com dois (medo e insegurança), 'a discriminação social dos alunos com deficiência' (quinta unidade de significado) com também dois (medo e insegurança), 'o não atendimento dos alunos com deficiência por professores especializados' (quarta unidade de significado) com um (insatisfação) e, 'a não participação do aluno com deficiência nas aulas' (sexta unidade de significado) com também um (impotência). Diante desse quadro de sentimentos, nos reportamos à Costa (2017, p.5) quando coloca que "[n]ão se pode mais ignorar a dimensão afetivo-emocional do docente frente à deficiência, pois essa tem se tornado cada vez mais presente [...]”. Ainda, achamos necessário citar Capellini e Mendes (2003) quando afirmam que os aspectos emocionais que surgem, por meio do contato com pessoas com deficiência, devem ser divulgados para que possam ser trabalhados.

Entretanto, nesse rol de sentimentos expressos, pelos professores de EF da EB, frente à Educação Inclusiva, podemos identificar uma 'totalidade de sentimentos negativos'. Segundo Rena et al. (2010, p.8), “[s]entimentos negativos como angústia, impotência, insegurança, solidão, desamparo e medo marcam o cotidiano de professor[e]s que trabalham com Educação Inclusiva. [...]”. Os autores ainda afirmam que esses sentimentos negativos "[...] sugerem um temor (=medo) permanente de não conseguir exercer de forma positiva o trabalho a que se propõe um professor, pois a demanda da inclusão chega às escolas antes da preparação das mesmas e de seu corpo docente" (RENA et al., 2010, p.8). De acordo com Krug et al. (2012), sentimentos negativos são aqueles 
que se originam do insucesso pedagógico e que a predominância destes pode levar o professor a ter uma ruptura profissional, ou seja, uma vontade de desistir da docência, isto devido a uma menor motivação para ser professor.

Assim, na intenção de compreensão dos sentimentos expressos, pelos professores de EF da EB, frente à Educação Inclusiva, citamos Luft (2000) que explicita os seus significados. São eles: a) insegurança-é a ausência de segurança; periculosidade. Sensação ou sentimento de não estar protegido, seguro; b) medo - temor, ansiedade irracional ou fundamentada; receio. Estado afetivo suscitado pela consciência do perigo ou que, ao contrário, suscita consciência. É um estado emocional que surge em resposta a consciência perante uma situação de eventual perigo; c) impotência - falta de poder, força ou meios para realizar algo; impossibilidade; d) angústia - estado de ansiedade, inquietude; sofrimento; e) ansiedade - é um estado psíquico de apreensão ou medo provocado pela antecipação de uma situação desagradável ou perigosa; f) pânico - situação de medo, desespero, aversão, susto, pavor repentino; e, g) insatisfação - falta de satisfação; descontentamento, desprazer, contrariedade, aborrecimento.

Dessa forma, podemos inferir que todos os desafios frente à inclusão de alunos com deficiência nas aulas de EFE, originam, consciente ou inconscientemente, sentimentos negativos, nas percepções dos professores de EF da EB estudados.

\section{As considerações conclusivas}

As informações coletadas e analisadas permitiram constatar a existência de um rol de seis desafios da docência, dos professores de EF da EB estudados, com alunos com deficiência incluídos nas aulas de EFE. Foram eles: 'a existência de alunos inclusos nas aulas de EF'; 'a falta de preparo/capacitação do próprio professor em lidar com alunos com deficiência nas aulas de EF'; 'a falta de acessibilidade/infraestrutura da escola'; 'o não atendimento dos alunos com deficiência por professores especializados'; 'a discriminação social dos alunos com deficiência'; e, 'a não participação do aluno com deficiência nas aulas de EF'.

Ao considerarmos esse rol de desafios da docência em EF na EB com alunos com deficiência nas aulas, destacamos que esses confirmaram que “[...] a prática pedagógica está sobre a influência de uma série de variáveis que permeiam o espaço educativo e por isso elas podem ser as mais diversas possíveis [...]” (KRUG et al., 2017a, p.10) e que, assim, consideramos que estas podem extrapolar as elencadas neste estudo.

Também constatamos que a 'metade' dos desafios elencados estão diretamente 'ligados à estrutura da escola/ sistema educacional' e a outra 'metade' dividida entre os 'ligados aos alunos da EB' e os 'ligados aos próprios professores'. Esse fato permite a constatação de que a inclusão dos alunos com deficiência nas aulas de EF na EB é ainda complexa para os professores de EF e que suscita a fomentação de debates acerca da inclusão escolar com o intuito de alargar os horizontes, pois, os depoimentos dos professores estudados possuem ainda muitas limitações para fazer a sua implementação. Nesse sentido, lembramos Krug et al. (2016, p.63) ao afirmarem que “[...] o processo de inclusão escolar ainda é um desafio a ser enfrentado devido à vários motivos, principalmente pela falta de estruturas físicas adequadas aos alunos com deficiência, bem como ao despreparo dos professores para atuar com os alunos". 
As informações coletadas e analisadas ainda permitiram constatarmos a existência de um rol de sete sentimentos expressos na docência, dos professores de EF da EB estudados, com alunos com deficiência incluídos nas aulas de EFE. Foram eles: 'a insegurança'; 'o medo'; 'a impotência'; 'a ansiedade'; 'a angústia'; 'o pânico'; e, 'a insatisfação', sendo a 'totalidade' destes, 'sentimentos negativos'. Nesse contexto, recordamos Mariano e Muniz (2006) quando afirmam que o trabalho docente pode ser identificado como fonte de sofrimento. E isso, aparentemente, foi o que ocorreu neste estudo, com os professores de EF da EB estudados ao atuarem com a inclusão escolar.

A partir destas constatações, proporcionadas pelas percepções dos professores de EF da EB estudados, sobre os desafios e os sentimentos expressos na docência com alunos incluídos nas aulas de EFE, podemos concluir que, apesar do respaldo legal, o sistema educacional, até hoje, não se estruturou realmente para o oferecimento de uma Educação Inclusiva, pois foram apontados vários desafios que originaram sentimentos negativos que são fonte de sofrimento para os docentes e, por consequência, dificultam a qualidade do ensino proporcionado aos alunos com deficiência. Essa conclusão é corroborada pela afirmação de Monteiro e Earp (2011) de que a inclusão escolar está cercada de inseguranças, incertezas e desafios para ser implementada.

Assim, diante dos resultados deste estudo, sugerimos a necessidade de uma discussão mais aprofundada que, segundo Krug et al. (2018b, p.67), “[...] já é histórica, sobre a inclusão escolar, para que as compreensões ou percepções limitadas sejam superadas pelos professores e que, desta forma, possam desenvolver práticas pedagógicas na escola de forma inclusiva”.

Referências

AMARAL, L. Pensar a diferença/deficiência. Brasília: CORDE, 1994.

ANJOS, H. dos. Professores e alunos com necessidades especiais enfrentam novos desafios. Revista Beira do Rio, Curitiba, a.VI., n.62, jun./jul. 2008.

BRASIL. Constituição da República Federativa do Brasil. Brasília: Senado Federal, 1988.

BRASIL. Política Nacional de Educação Especial na perspectiva da Educação Inclusiva. Brasília: MEC/SEE, 2008.

BRASIL. Ministério da Educação. Lei de Diretrizes e Bases da Educação Nacional - Lei n.9.394, de 20 de dezembro de 1996.

CAPELLINI, V.; MENDES, E. Informação e sensibilização: primeiros passos para a inclusão. São Carlos: UFSCar, 2003.

CARVALHO, C.L. de; ARAÚJO, P.F. de. Inclusão escolar de alunos com deficiência: interface com conteúdos da Educação Física. Revista Educación Física y Ciência, La Plata, v.20, n.1, e.041, p.1-15, 2018. Disponível em: http://www.efyc.fahce.unlp.edu.ar/view/EFyCe041/9300 . Acesso em: 04 jul. 2018. 
CONCEIÇÃO, V.J.S. da; KRUG, H.N; SANTOS JÚNIOR, S.L. dos; KRÜGER, L.G.; ZANINI, M.C.; SILVA, M.S. da O perfil do professor de Educação Física no ensino fundamental em Santa Maria (RS). In: SIMPÓSIO NACIONAL DE EDUCAÇÃO FÍSICA, XXIII., 2004, Pelotas. Anais, Pelotas: ESEF/UFPel, 2004. CD-ROOM.

CONCEIÇÃO, V.J.S. da; SOUZA, T. de; KRUG, H.N. Saberes docentes e atuação profissional do professor de Educação Física no ensino regular com alunos com necessidades educacionais especiais incluídos. Revista Digital Lecturas: Educación Física y Deportes, Buenos Aires, a.15, n.148, p.1-6, sep. 2010. Disponível em: http://www.efdeportes.com/efd148/atuacao-profissional-com-alunos-comnecessidades... . Acesso em: 12 jun. 2018.

CONCEIÇÃO, V.J.S. da; KRUG, H.N.; VENSON, E. Mobilizando saberes docentes na Educação Física Escolar: a construção do conhecimento sobre inclusão. Revista Educação Especial, Santa Maria, v.26, n.46, p.465-484, 2013.

COSTA, M.C.S. da. Sentimentos de professores frente às dificuldades na prática da educação inclusiva de alunos com deficiência no ensino fundamental, 2007. Dissertação (Mestrado em Psicologia da Educação) - Pontifícia Universidade Católica de São Paulo, São Paulo, 2007.

DINIZ, M.; RAHME, M. Da Educação Especial à Educação Inclusiva. In: DINIZ, M.; VASCONCELOS, R.N. (Orgs.). Pluralidade cultural e inclusão na formação de professores: gênero, sexualidade, raça, Educação Especial, Educação Indígena, Educação de Jovens e Adultos. Belo Horizonte: Formato Editorial, 2004.

FERNANDES, L.S.; VARGAS, L.; FALKENBACK, A.P. Paradesporto futsal para cegos: um estudo das motivações dos atletas participantes. Revista Digital Lecturas: Educación Física y Deportes, Buenos Aires, a.14, n.132, p.1-11, mai. 2009. Disponível em: http://www.efdeportes.com/efd132/ paradesporto-futsal-para-cegos.htm. Acesso em: 04 set. 2018.

FREITAS, A.F.S.; LEUCAS, C.B. de. O desafio da inclusão: o professor de Educação Física e a construção do processo de ensino e aprendizagem com a participação de um aluno com deficiência. In: CONGRESSO BRASILEIRO DE CIÊNCIAS DO ESPORTE E CONGRESSO INTERNACIONAL DE CIÊNCIAS DO ESPORTE, XVI., III., Salvador, 2009. Anais, Salvador, 2009.

GOLDENBERG, M. A arte de pesquisar: como fazer pesquisa qualitativa em ciências sociais. 8. ed. Rio de Janeiro/São Paulo: Editora Record, 2004.

GONÇALVES, J.A. A carreira dos professores do ensino primário. In: NÓVOA, A. (Org.). Vidas de professores. Porto: Porto Editora, 1992.

KRUG, H.N. A inclusão de pessoas portadoras de necessidades especiais na Educação Física Escolar. Revista Cadernos de Educação Especial, Santa Maria, n.19, p.15-23, 2002.

KRUG, H.N. Estágio Curricular Supervisionado no ensino médio: os sentimentos expressos pelos acadêmicos da Licenciatura em Educação Física do CEFD/UFSM. Revista Gestão Universitária, Belo Horizonte, p.1-9, nov. 2017. Disponível em: http:/www.gestaouniversitaria.com.br/artigos/ estagio-curricular-supervisionado-no-ensino-medio-os-sentimentos-expressos-pelos-academicos-da... . Acesso em: 12 jun. 2018. 
KRUG, H.N.; ANTUNES, F.R.; MAZZOCATO, A.P.F.; CARAMÊS, A. de S.; CASAROTTO, V.J. Os sentimentos expressos pelos acadêmicos da Licenciatura em Educação Física do CEFD/UFSM durante a experiência docente no Estágio Curricular Supervisionado. Revista Digital Lecturas: Educación Física y Deportes, Buenos Aires, a.17, n.172, p.1-7, sep. 2012. Disponível em: http://www.efdepotes. com/efd172/os-sentimentos-expressos-pelos-academicos.htm. Acesso em: 04 set. 2018.

KRUG, H.N.; CONCEIÇÃO, V.J.S. da; TELLES, C.; KRUG, R. de R.; FLORES, P.P.; KRUG, M. de R. Educação Física Escolar inclusiva: dilemas e perspectivas. Revista Querubim, Niterói, a.12, n.28, v.02, p.58-64, 2016.

KRUG, H.N.; CONCEIÇÃO, V.J.S. da; TELLES, C.; KRUG, R. de R.; FLORES, P.P.; KRUG, M. de R. As dificuldades enfrentadas pelos acadêmicos de Educação Física em situação de Estágio Curricular Supervisionado frente aos alunos com deficiência. Revista Itinerarius Reflectionis, Jataí, v.13, n.1, p.1-13, 2017a.

KRUG, H.N.; CONCEIÇÃO, V.J.S. da ; KRUG, R. de R.; TELLES, C. Diversidade humana e inclusão social na escola na percepção de acadêmicos de Educação Física em situação de Estágio Curricular Supervisionado. Brazilian Journal of Education Society (BRAJETS), v.10, n.4, p.366375 , out./dez. 2017 b.

KRUG, H.N.; KRUG, R. de R.; KRUG, M. de R.; TELLES, C.; FLORES, P.P. As marcas docentes no início da carreira de professores de Educação Física na Educação Básica. Revista Triângulo, Uberaba, v.10, n.1, p.56-72, jan./jun. 2017c.

KRUG, H.N.; CONCEIÇÃO, V.J.S. da; KRUG, M. de R.; KRUG, R. de R.; FLORES, P.P. Ser futuro professor surdo-mudo de Educação Física: escolha, compreensões e perspectivas. Revista Itinerarius Reflectionis, Jataí, v.14, n.1, p.1-19, 2018a.

KRUG, H.N.; KRUG, M. de R.; KRUG, R. de R.; TELLES, C. A inclusão de alunos com deficiência nas aulas de Educação Física: vantagens e desvantagens. Revista Formação@Docente, Belo Horizonte, v.10, n.1, p.58-69, jan./jun. 2018 b.

LEHNHARD, G.R.; MANTA, S.W.; PALMA, L.E. Inclusão na Educação Física: concepções de gestores e professores sobre a participação dos alunos com deficiência física. In: SEMINÁRIO INTERINSTITUCIONAL DE ENSINO, PESQUISA E EXTENSÃO, XVI., 2011, Cruz Alta. Anais, Cruz Alta: UNICRUZ, 2011.

LIMA, F.J.; SILVA, F.T. dos S. Barreiras atitudinais: obstáculos à pessoa com deficiência física na escola. In: SOUZA, O.S.H. (Org.). Itinerários da inclusão escolar: múltiplos olhares, saberes e práticas. Canoas: Ed. ULBRA/Porto Alegre: AGE, 2008.

LIMA, L.F.; SANTOS, C. das S.; SILVA, R.P. de S. O profissional da Educação Física e a inclusão dos alunos com deficiência no ensino regular. Revista Poiésis Pedagógica, Catalão, v.5/6, p.125-145, jan./ dez. 2007/2008.

LOURENCETTI, G. do C.; MIZUKAMI, M. da G.N. Dilemas de professores em práticas cotidianas. In: MIZUKAMI, M. da G.N.; REALI, A.M. de M.R. (Orgs.). Aprendizagem profissional da docência: saberes, contextos e práticas. São Carlos: EdUFSCar, 2002. 
LUFT, C.P. MiniDicionário Luft. São Paulo: Ática/Scipione, 2000.

LUIZARI, D.C.M. Estudo dos ciclos de vida e de carreira, inclinação profissional e crenças pessoais, 2006. Dissertação (Mestrado em Gestão e Desenvolvimento Regional) - Universidade de Taubaté, Taubaté, 2006.

MANZINI, E.J. Participação em aulas de Educação Física: o que alunos com defíciência visual e física relatam. Coleção Prata da Casa, V. Especial, n.1, p.81-85, 2002.

MARIANO, M. do S.S.; MUNIZ, H.P. Trabalho docente e saúde: o caso dos professores da segunda fase do ensino fundamental. Revista Estudos e Pesquisas em Psicologia, Rio de Janeiro, v.6, n.1, jun. 2006.

MARQUES, M.N.; KRUG, R. de R.; KRUG, H.N.; CONCEIÇÃO, V.J.S. da Os desafios do cotidiano educacional: o caso da Educação Física. Revista Roteiro, Joaçaba, v.40, n.1, p.187-206, 2015.

MINAYO, M.C.S.; DESLANDES, S.F.; GOMES, R. (Orgs.). Pesquisa social: teoria, método e criatividade. 32. ed. Petrópolis: Vozes, 2007.

MOLINA NETO, V. Etnografia: uma opção metodológica para alguns problemas e investigação no âmbito da Educação Física. In: MOLINA NETO, V.; TRIVIÑOS, A.N.S. (Orgs.). A pesquisa qualitativa em Educação Física: alternativas metodológicas. Porto Alegre: Sulina, 2004.

MONTEIRO, M. da G.T.; EARP, M. de L.S. Um estudo qualitativo sobre inclusão escolar. Revista Olhar de Professor, Ponta Grossa, v.14, n.1, p.183-200, 2011.

NAUJORKS, M. et al. Stress ou Burnout, a realidade frente à inclusão. Cadernos de Educação Especial, n.15, Santa Maria, p.67-74, 2000.

PALMA, L.E.; LEHNHARD, G.R. Aulas de Educação Física e inclusão: um estudo de caso com a deficiência física. Revista Educação Especial, Santa Maria, v.25, n.42, p.115-126, 2012.

PONTE, J.P. da. Estudos de casos em Educação Matemática. Revista Bolema, Rio Claro, v.19, n.25, p.105-132, 2006.

RENA, L.C.C.B. et al. Docência e inclusão: sentimentos e desafios de professores na escola pública. In: SEMINÁRIO SOCIEDADE INCLUSIVA: os discursos sobre o outro e as práticas sociais, VI., Belo Horizonte, 2010. Anais, Belo Horizonte, 2010. p.1-16.

SAGRILO, L.C.; PAIM, M.C.C. Sentimentos que permeiam o processo de inclusão de alunos portadores de deficiência visual. Revista Digital Lecturas: Educación Física y Deportes, Buenos Aires, a.14, n.133, p.1-10, jun. 2009. Disponível em: http://www.efdeportes.com/efd133/inclusao-dealunos-portadores-de-deficiencia-visual.htm. Acesso em: 11 jun. 2018.

SANTOS, S.G. dos; MORETTI-PIRES, R.O. (Orgs.). Métodos e técnicas de pesquisa qualitativa aplicada à Educação Física. Florianópolis: Tribo da Ilha, 2012. 
SASSAKI, R.K. Inclusão: o paradigma do século 21. Inclusão - Revista da Educação Especial, Brasília, p.19-23, out. 2005. Disponível em: http://www.portal.mec.gov.br/seesp/arquivos/pdf/ revistainclusao.pdf. Acesso em: 12 jun. 2018.

SEABRA JUNIOR, L. Inclusão, necessidades especiais e Educação Física: considerações sobre a ação pedagógica no ambiente escolar, 2006. Dissertação (Mestrado em Educação Física) - UNICAMP, Campinas, 2006.

SERRA, D.C.G. Teorias e práticas da Psicologia institucional. Curitiba: Lesde, 2006.

SOUZA, J.V.; MIRANDA, D.D. A tutoria como estratégia de ensino nas aulas de Educação Física na rede regular de Ilhéus-Bahia. In: CONGRESSO BRASILEIRO DE EDUCAÇÃO ESPECIAL, IV., 2010, São Carlos. Anais, São Carlos: UFSCar, 2010.

TELLES, C.; KRUG, H.N. A inclusão de alunos com deficiência na Educação Física Escolar. Revista Gestão Universitária, Belo Horizonte, p.1-9, jul. 2014. Disponível em: http://www. gestaouniversitaria.com.br/artigos/a-inclusao-de-alunos-com-deficiencia-na-educacao-fisica-escolar. Acesso em: 12 jun. 2018.

TESSARO, N.S. Inclusão escolar: concepções de professores e alunos da educação regular e especial. Campinas: Associação Brasileira de Psicologia Escolar e Educacional, 2007.

TRIVIÑOS, A.N.S. Introdução à pesquisa em ciências sociais - pesquisa qualitativa em educação. São Paulo: Atlas, 1987.

TURATO, E.R. Tratado da metodologia da pesquisa clínico-qualitativa: construção teóricoepistemológica, discussão comparada e aplicação nas áreas da saúde e humanas. 2. ed. Petrópolis: Vozes, 2003.

Recebido em 22/01/2019

Aprovado em 30/05/2019 
